Reviews in Digital Humanities • Vol. 1, No. 10

\title{
Review: Digital \\ Transgender Archive
}

Nikita Shepard ${ }^{1}$

${ }^{1}$ Columbia University

Published on: Oct 05, 2020

DOI: $10.21428 / 3 e 88 f 64 f .7 b e d e 3 f d$

License: Creative Commons Attribution 4.0 International License (CC-BY 4.0). 


\section{Project}

Digital Transgender Archive

\section{Project Director}

K.J. Rawson, Northeastern University

Project URL

https://www.digitaltransgenderarchive.net/

\section{Project Reviewer}

Nikita Shepard, Columbia University

\section{Project Overview}

\section{K.J. Rawson}

Launched in early 2016, the Digital Transgender Archive (DTA) is a freely available online project dedicated to improving access to transgender-related history. The collection includes digitized historical materials, born-digital materials, and discovery resources (such as finding aids and collection guides). All of the materials on the site ( 8,300 items, as of February 2020) have been contributed by more than 60 partnering institutions located in 9 different countries. These contributing institutions vary widely-from elite universities to grassroots archives-and the types of materials they have contributed are equally varied (such as photographs, clippings, periodicals, correspondence, ephemera, etc.). The site also includes educational resources, such as a DTA “Starter's Guide,” a “Global Terms List," and a "Race \& Ethnicity Research Guide."

The collection focuses on materials created anywhere in the world prior to 2000, with more recent items included if their focus is on pre-2000 history. Since the term "transgender" is a relatively recent and culturally-specific identity, the DTA includes materials related to practices of trans-ing gender (i.e., transgressions of gender norms), irrespective of the identities of the people involved. This is a broad and inclusive scope that is designed to be historically and culturally capacious, and it is intended to support the project's ongoing and indefinite expansion.

The team behind the DTA includes founder and director K.J. Rawson, software developer Steven Anderson, dozens of student research assistants and volunteers. From 2017-2019, the team also included digital archivist Nicole Tantum. The software 
stack is built using Samvera (formerly Hydra), and the codebase is available on GitHub. Digitization and processing is done either by our partnering institutions or, before the project moved to Northeastern, in our lab at the College of the Holy Cross.

The DTA has received two major grants from the American Council of Learned Societies (a 2015-2016 Digital Innovation Fellowship and a 2017-2018 Digital Extension Grant), and the project has been further supported by the College of the Holy Cross. In 2017, the Society of American Archivists awarded the DTA the C.F.W. Coker Award for Archival Description in recognition of the project's impact on setting national standards.

Usage of the site has been strong, with $\sim 1.5$ million pageviews and an average session duration of over 4 minutes (as of February 2020). The DTA has been publicized in dozens of media outlets, is used extensively in secondary and higher education classrooms, has been a source for documentaries, podcasts, and television shows, and has been cited in countless scholarly works. This sustained and rich usage demonstrates that the DTA offers a valuable scholarly resource while also providing important enrichment for broad public knowledge of transgender issues, which is a key goal of the project.

\section{Project Review}

\section{Nikita Shepard}

Scholars exploring gender diversity of the past face a variety of barriers, from the obscurity and inaccessibility of archival material to search challenges due to inconsistent terminology and indexing. In response, the creators of the Digital Transgender Archive (DTA) have compiled thousands of digitized and born-digital materials relevant to transgender history from dozens of institutions into an easily navigable web platform. Expansively defining transgender as a "broad and inclusive range of non-normative gender practices" rather than a specific identity category, the DTA has assembled what it describes as "a trans-historical and trans-cultural collection of materials related to trans-ing gender." Its geographic scope centers on North America but incorporates material from around the world, primarily from the 20th century but stretching back at least to the 1500s. Based at Northeastern University (formerly at College of the Holy Cross) and supported in part by funding from the American Council of Learned Societies, the DTA is directed by K.J. Rawson and 
supported by an advisory board of that includes both transgender and cis-gender activists and scholars along with a team of students and volunteers.

The heart of the DTA lies in the many pathways it offers for sorting and searching its varied materials. The "Institutions" feature indexes the dozens of repositories whose material populates the site, ranging from university libraries to topical collections to community archives based primarily online or in North America but with contributors from Europe and Latin America. The "Collections" feature allows users to browse over 100 widely varied thematic clusters of material, indicating categories (court documents, sheet music), individuals (the Lou Sullivan or Christine Jorgensen collections), publications (Hermaphrodites with Attitude, Transgender Tapestry), and more. The "Topic" function reveals an expansive, sophisticated index of searchable metadata terms, reflecting Rawson's work with Homosaurus, an influential linked data vocabulary of LGBTQ+ terms, while "Genre" allows users to peruse material by formats ranging from photographs to oral histories to posters. The interactive "Map" function, while elegantly designed with Leaflet, proves counter-intuitive by positioning items based neither on where they were produced nor their archival location but on any geographic reference made in the content of the item, blurring the topic or subject fields and reducing its utility. With this exception, these varied search axes provide multiple useful points of entry to navigate the growing collection.

For users new to transgender history, the DTA offers a "Starter's Guide." The "Glossary" and "Global Terms" pages provide definitions for a wide range of concepts not limited to contemporary Euro-American gender frameworks, while a series of questions reflecting popular interests and uses for the site offer accessible introductions to its content. The "Race and Ethnicity Research Guide" links to BIPOCrelated materials, search advice, and a description of metadata policies relating to race. Written in accessible language and offering tips on allyship, the "Starter's Guide" reflects a community orientation that expands the DTA's relevance beyond the academy. The Digital Transgender Archive models how digital humanities projects can engage and remain accountable to broad communities of users, while providing an invaluable resource for both scholarly researchers and community members curious about their history. 